\title{
Professores da educação básica Conhecimento prévio e problematização
}

\author{
Natanael Feijó* \\ Nadir Castilho Delizoicov ${ }^{* *}$
}

\begin{abstract}
RESUMO: Neste trabalho discute-se a questão do conhecimento que os alunos já detêm quando chegam à escola e a necessidade de os professores problematizá-lo. A pesquisa se desenvolveu na perspectiva qualitativa e o instrumento de coleta de dados, a entrevista semiestruturada. Os professores ministram Geografia em escolas públicas estaduais. Os resultados indicam que os professores têm dificuldades em problematizar esse conhecimento, pressupondo-se lacunas na formação.
\end{abstract}

Palavras-chave: Conhecimento prévio. Problematização. Ensino-aprendizagem.

\section{Teachers of basic education Prior knowledge and problem setting}

\begin{abstract}
In this work we discuss the question of knowledge which students already possess when they start school, and the teachers need to problem set it. The research has been developed from a qualitative perspective and data collection was obtained through semistructured interviews. The teachers teach geography in public state schools. The results indicate that the teachers
\end{abstract}

* Mestre em Educação. Atua como professor em licenciaturas da Universidade Comunitária da Região de Chapecó (Unochapecó) e participa do grupo de Pesquisa: Ensino e formação de professores. Chapecó/SC Brasil. E-mail: <natanaelf@unochapeco.edu.br>.

** Doutora em Educação. Professora Titular no Mestrado em Educação do Centro de Ciências Humanas e Jurídicas da Universidade Comunitária da Região de Chapecó (Unocapecó), professora colaboradora do Programa de Pós Graduação em Educação Científica e Tecnológica da Universidade Federal de Santa Catarina (PPGECT/UFSC) e pesquisadora no grupo de pesquisa "Ensino e Formação de Professores", cadastrado no CNPq. Atuou como professora da educação básica por cerca de 20 anos. Chapecó/SC - Brasil. E-mail:<ridanc.nadir@gmail.com>. 
encounter difficulties in problem setting this prior information, which assumes gaps in formation.

Key words: Prior knowledge. Problem setting. Teaching-learning.

\section{Profesores de la educación básica}

Conocimiento previo y cuestionamiento

RESUMEN: En este trabajo se discute la cuestión del conocimiento que tienen los alumnos cuando llegan a la escuela y la necesidad de que los profesores lo cuestionen. La investigación se ha llevado a cabo con un enfoque cualitativo y el instrumento para la recolección de datos ha sido la entrevista semiestructurada. Los profesores imparten la asignatura de Geografía en escuelas públicas del estado. Los resultados indican que los profesores tienen dificultades para cuestionar ese conocimiento, suponiéndose lagunas en la formación.

Palabras clave: Conocimiento previo. Cuestionamiento. Enseñanza/ aprendizaje.

\section{Enseignants de l'éducation basique}

Connaissance préalable et problématisation

RÉSUMÉ: Cet article traite de la question de la connaissance que les éléves possédent déjà quand ils entrent à l'école et de la nécessité pour les enseignants de la problématiser. La recherche s'est établie à partir de la perspective qualitative et de l'outil de collecte de données, l'entrevue semi-strucutrée. Les enseignants donnent des cours de géographie dans des écoles publiques du réseau d'état. Les résultats montrent que les enseignants rencontrent des difficultés pour problématiser cette connaissance, ce qui démontre des lacunes dans leur formation.

Mots-clés: Connaissance préalable. Problématisation.

Enseignement-apprentissage. 


\section{Introdução}

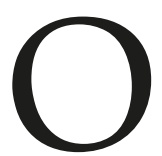

processo ensino-aprendizagem tem sido temática constante de estudos e pesquisas ao longo da história da educação brasileira. Em cada momento histórico, concepções de educação e ensino-aprendizagem orientam as práticas pedagógicas, visando a formação de sujeitos que atendam as demandas sociais. Hoje, por exemplo, há a perspectiva de uma educação escolar que proporcione a formação de cidadãos autônomos, críticos, com capacidade de refletir sobre a própria realidade e contribuir para transformá-la.

É consenso entre educadores (SANTOS, 2012; MESSEDER NETO; PINHEIRO; ROQUE 2013; BELLUCO; CARVALHO, 2014 entre outros) que todo sujeito, quando chega à escola, traz consigo uma compreensão do mundo que o cerca. São conhecimentos adquiridos no meio em que vive, denominados de conhecimentos prévios que, geralmente, não estão em sintonia com aqueles produzidos pela ciência. Os conhecimentos prévios, também chamados de concepções alternativas ou senso comum, se não forem adequadamente problematizados, podem interferir no processo de aprendizagem do aluno, dificultando a apropriação do conhecimento sistematizado.

Com o objetivo de investigar a compreensão dos professores sobre conhecimentos prévios dos alunos e as maneiras pelas quais lidam com esses saberes, foi realizada uma pesquisa (FEIJÓ, 2015), que se pautou na abordagem qualitativa, a qual, segundo Minayo (2008, p. 57), aplica-se ao estudo "[...] das relações, das representações, das crenças, das percepções e das opiniões, produtos das interpretações que os humanos fazem a respeito de como vivem, constroem seus artefatos e a si mesmos, sentem e pensam". Como instrumento para coleta de dados, utilizou-se a entrevista semiestruturada que, de acordo com Triviños (1987, p. 146), “[...] ao mesmo tempo que valoriza a presença do investigador, oferece todas as perspectivas possíveis para que o informante alcance a liberdade e espontaneidade necessárias, enriquecendo a investigação".

A entrevista semiestruturada foi organizada em sete questões, sendo uma delas aberta, visando oportunizar aos professores fornecerem outras informações que julgassem importantes. Assim, dez professores que trabalham na rede pública do município de Chapecó, ministrando a disciplina de Geografia para o Ensino Médio, participaram do estudo. As entrevistas foram gravadas, transcritas e submetidas à apreciação dos professores para garantir a fidedignidade. Com o objetivo de preservar o sigilo necessário na identificação dos entrevistados, os professores estão nomeados com números, acompanhados da letra " $\mathrm{P}$ ". A pesquisa foi submetida e aprovada pelo comitê de ética em pesquisa envolvendo seres humanos da Universidade Comunitária da Região de Chapecó (Unochapecó). 


\section{O conhecimento prévio do aluno}

Os conhecimentos prévios advêm das relações que o sujeito estabelece ao longo da vida, de acordo com o seu meio social e cultural. Esses conhecimentos são constituídos por influência familiar, religiosa, política, econômica, intelectual, " [...] aquilo a que chamamos habitualmente de senso comum consiste numa série de crenças admitidas no seio de uma determinada sociedade, que seus membros presumem ser partilhadas por todo ser racional" (PERELMAN; OLBRECHTS, 2005, p. 112).

Paulo Freire (1980, p. 25-26) chama a atenção para a relação do sujeito com o meio em que vive, para ele "[...] os homens são capazes de agir conscientemente sobre a realidade objetivada. É precisamente isto, a 'práxis humana', a unidade indissolúvel entre minha ação e minha reflexão sobre o mundo". A "práxis humana" a que Freire (1980) se refere resulta em conhecimentos, na medida em que o sujeito os reflete, conhece e constrói; nesse processo natural vai se "humanizando" e, de forma autônoma, vai fazendo escolhas.

Sobre a influência que o meio social tem na constituição dos conhecimentos prévios, Alves (2012, p. 188) afirma que, " [...] tanto Freire quanto Vigotski concebem o processo de conhecimento como fenômeno cuja produção depende da relação de troca, de interação, que se efetiva e se caracteriza fundamentalmente pela mediação social".

Freire (1987) também se refere ao "ser mais" que, para ele, trata-se da capacidade que o homem tem de crescer intelectualmente, mas não crescer em detrimento do sofrimento ou opressão do próximo, ao que ele denomina de desumanização. O "ser mais" é característica exclusiva do ser humano, pois raciocina, reflete, constrói pensamentos, evolui intelectualmente. Quando o ser humano não exerce essa característica única, está negando sua ontologia. É necessário que o homem tenha consciência de que pode ser mais; a conscientização é, “[...] antes de tudo, um esforço para livrar os homens dos obstáculos que os impedem de ter uma clara percepção da realidade" (FREIRE, 1980, p. 94).

Nesse sentido, encontra-se em Bachelard (1996) o conceito de "obstáculo epistemológico", compreendido como impedimentos que retardam o ser humano de chegar ao real conhecimento (mesmo que esse "real" conhecimento não seja estático). Embora o autor refira-se prioritariamente ao conhecimento científico, todo processo de construção de conhecimentos assemelha-se.

Ao retomar um passado cheio de erros, encontra-se a verdade num autêntico arrependimento intelectual. No fundo, o ato de conhecer dá-se contra um conhecimento anterior, destruindo conhecimentos mal estabelecidos, superando o que, no próprio espírito, é obstáculo à espiritualização. (BACHELARD, 1996, p. 17).

De acordo com o senso comum, há uma verdade pronta e acabada. Essa concepção pode se constituir como obstáculo para a evolução do sujeito. Conhecimentos que 
foram considerados por diversos anos como imutáveis acabaram alterados, como por exemplo, a crença que o Sol girava em torno da Terra:

[...] da observação que o Sol nasce todos os dias de um lado da Terra e se põe do outro, o homem pensou, por muito tempo, que o Sol girava em torno da Terra. Essa compreensão do fenômeno pareceu satisfatória durante séculos, sem mais provas do que a simples observação. Em nossa linguagem de hoje, chamam-se tais explicações espontâneas de 'senso comum', às vezes de 'simples bom-senso'. Ora, o senso comum e, com frequência, enganador. Acreditar que o Sol gira em torno da Terra e uma ilustração patente disso. (LAVILLE; DIONNE, 1999, p. 20).

Embora a afirmação dos autores seja bastante crítica em relação ao papel do conhecimento do senso comum, isso não deve servir de obstáculo ao contínuo processo de construção de conhecimentos sistematizados. Pelo contrário, pode constituir a base para que novos conhecimentos possam ser construídos.

As descobertas e rupturas que ocorrem no processo de construção do conhecimento são devidas à típica curiosidade do ser humano, pois o processo de desenvolvimento de uma pergunta ocorre juntamente com o desenvolvimento dos conhecimentos adquiridos pelo sujeito. Bachelard (1996, p. 18) afirma que o conhecimento só existe quando há pergunta: "Para o espírito científico, todo conhecimento é resposta a uma pergunta. Se não há pergunta, não pode haver conhecimento científico" .

A produção do conhecimento procura atender prioritariamente ao mundo das necessidades. Para Gamboa (2013), além da curiosidade, o homem tem necessidades básicas e busca formas eficazes para atendê-las. O aluno quando chega à escola busca suprir curiosidades e necessidades, pois traz consigo uma bagagem de conhecimentos os quais precisam ser problematizados durante o processo ensino-aprendizagem, pois o objetivo é que eles sejam transformados, para que o aluno incorpore conscientemente conhecimentos sistematizados, os quais o ajudarão a melhor compreender fenômenos naturais e sociais.

Na seção que segue, discute-se como os professores lidam com os conhecimentos prévios dos alunos em sala de aula, tomando-se por base os dados coletados em uma pesquisa que ouviu professores da rede pública do município de Chapecó.

\section{Os professores e os conhecimentos prévios dos alunos}

Com frequência, muitos professores atribuem a falta de interesse dos alunos,como uma das causas que impedem a apropriação do conhecimento científico, não considerando que a dificuldade possa estar relacionada à forma como esse conhecimento é abordado em sala de aula. A falta de motivação pode estar associada às concepções prévias que os alunos trazem para a escola. Elas podem se constituir no que Bachelard 
(2001) denomina de "obstáculo pedagógico", caso os professores não tomem como ponto de partida esses conhecimentos para desencadear o processo de ensino-aprendizagem.

Não reflectiram no facto de que o adolescente chega à aula de física com conhecimentos empíricos já constituídos: trata-se, então, não de adquirir uma cultura experimental, mas sim de mudar de cultura experimental, eliminar os obstáculos já acumulados pela vida quotidiana. (BACHELARD, 2001, p. 168).

Assim, identificar a compreensão que os professores têm sobre os conhecimentos prévios dos alunos e se os consideram ou não, no processo ensino-aprendizagem, pode contribuir para avançar nessa discussão.

Com esse objetivo, realizou-se uma investigação com dez professores de Geografia que ministram aula na educação básica. Os professores responderam a uma entrevista semiestruturada composta por sete questões. Para este texto, foram consideradas apenas duas delas, quais sejam: a compreensão dos docentes sobre conhecimentos prévios e como lidam com esses conhecimentos em sala de aula.

Inicialmente, os professores foram solicitados a se posicionar quanto aos conhecimentos prévios ou concepções alternativas dos alunos, conforme segue:

[...] esse senso comum, é o tal do 'diz que diz que', do achismo, eu acho que isso é o senso comum, o que a gente vive no dia a dia (P2); [...] eu acredito que esse conhecimento prévio ele vem, $[\ldots]$ um pouco de casa esse conhecimento prévio deles, porque tem muito a questão da $\mathrm{TV}$, a convivência no dia a dia, entre outros (P4); [...] é a bagagem que cada um tem [...] a opinião pessoal, aquilo que você traz, eu acredito que é aquilo que cada um tem, [...] você vai formando a tua concepção (P8); [...] esse conhecimento comum que eles trazem para a escola [...] às vezes o pai comenta, a mãe comenta, a vizinha comenta então é o senso comum, [...] eles vão criando na cabecinha deles os conceitos de acordo com a sociedade (P9).

É possível observar que os docentes demonstram compreender que os conhecimentos prévios dos alunos são oriundos da vivência em família, com a mídia, com os amigos, com a sociedade, enfim, são conhecimentos oriundos das relações que o indivíduo estabelece com o meio em que vive. Na compreensão do professor P5, há uma diferenciação quanto à qualidade dos conhecimentos prévios, ou seja, se o indivíduo vive em um ambiente no qual as pessoas com as quais se relaciona têm alto nível de escolaridade e também maior acesso a informações, o conhecimento prévio desse sujeito será mais elaborado do que daquele que convive com pessoas menos escolarizadas e com menor acesso aos meios de comunicação. É o que se observa no seu depoimento.

[...] os alunos [...] maiores têm um conhecimento um pouco mais aprofundado e os pequenos trazem o senso comum de casa, é a relação da família com o conhecimento. Então se o pai e a mãe estudaram, por exemplo, têm nível superior, vocêjá percebe no aluno. Se os pais têm o nível de estudo um pouco mais baixo, o senso comum, o conhecimento que o aluno traz é bem mais raso, as coisas são mais 
simples, então tem a ver com o conhecimento da família. Se a família assiste jornal, se ela comenta assuntos com o filho, esse conhecimento vai vir pra escola. (P5).

Vigotski (1998) destaca que o meio social tem peso importante no desenvolvimento do sujeito. Também Paulo Freire (1987) argumenta que a identidade cultural do aluno é constituída pelas vivências cotidianas. Assim, seja qual for a condição social e econômica do sujeito, o meio em que ele vive exerce influência em seus conhecimentos prévios, mesmo que tenham alguma base científica, pois são conhecimentos que ele já detém ao chegar à escola. Já Moreira e Masini (2001, p. 23) advertem que, para ocorrer a aprendizagem significativa, é necessário que "[...] o aprendiz manifeste uma disposição de relacionar o novo material de maneira substantiva e não-arbitrária à sua estrutura cognitiva". Sendo assim, os professores têm papel importante na conscientização do aluno sobre a necessidade de rever os conhecimentos prévios para que ele possa se apropriar de conhecimentos sistematizados de tal forma que façam sentido para ele, que sejam significativos.

Vale a pena nos reportarmos a Bachelard (2001, p. 168), quando o autor adverte que "[...] muitas vezes me tenho impressionado com o facto de os professores [...] não compreenderem que não se compreenda". Ou seja, o professor não deveria estranhar a dificuldade que o aluno tem em apropriar-se do conhecimento sistematizado, e sim buscar identificar a causa que o está impedindo de aprender.

Os professores possuem uma compreensão sobre os conhecimentos prévios dos alunos a qual se aproxima ao que está descrito na literatura. Resta saber como lidam com isso em sala de aula. Esse é o foco da seção a seguir.

\section{A ação do professor e os conhecimentos prévios dos alunos}

Para que o aluno reconheça que os conhecimentos prévios que traz não dão conta de ajudá-lo no enfrentamento de problemas e na compreensão consistente de fenômenos naturais e situações vivenciadas em seu cotidiano, faz-se necessária a intervenção da escola. Para tanto, os professores lançam mão de distintas estratégias.

[...] é para problematizá-lo que o professor deve apreender o conhecimento já construído pelo aluno; para aguçar as contradições e localizar as limitações desse conhecimento, quando cotejado com o conhecimento científico, com a finalidade de propiciar um distanciamento crítico do educando, ao se defrontar com o conhecimento que ele já possui, e, ao mesmo tempo, propiciar a alternativa de apreensão do conhecimento científico. (DELIZOICOV; ANGOTTI; PERNAMBUCO, 2007, p. 199). 
Essa problematização exige, por parte do docente, tempo e planejamento, pois deverá lançar um problema que contenha uma contradição, como um desafio, para que os alunos sintam a necessidade de buscar o conhecimento sistematizado para ajudá-los na resolução do que foi proposto. A função do problema é desencadear uma sequência, denominada por Delizoicov, Angotti e Pernambuco (2007) como Três Momentos Pedagógicos, quais sejam: Problematização Inicial, Organização do Conhecimento e Aplicação do Conhecimento. Na Problematização Inicial, apresentam-se questionamentos relacionados aos conhecimentos prévios, com a finalidade de apreender os saberes dos alunos. Na Organização do Conhecimento, o professor poderá utilizar diferentes estratégias para introduzir o conhecimento sistematizado que ajudará na resolução do problema proposto. Por último, na Aplicação do Conhecimento, o professor retoma novamente a Problematização Inicial para que o aluno reconheça que o novo conhecimento é capaz de fornecer soluções mais consistente para o problema.

No entanto, por razões diversas, inclusive por não estar preparado para agir de forma a considerar e problematizar as concepções alternativas do aluno, muitas vezes, o professor " [...] acaba por ceder a vez ao instinto conservativo. Chega o momento em que o espírito prefere o que confirma o seu saber àquilo que o contradiz [...] (BACHELARD, 1996, p. 19).

Com o objetivo de verificar como os professores lidam com os conhecimentos prévios dos alunos, perguntou-se a eles se problematizam ou não esses conhecimentos.

Uma das ações citadas pelos docentes foi que iniciam a discussão de um assunto por meio do diálogo, para identificar aquilo que os alunos já sabem sobre o tema a ser abordado. Nesse sentido, Paulo Freire (1987, p. 68) afirma que no diálogo há troca de conhecimento, e nessa troca o professor e o aluno aprendem, “[...] o educador já não é o que apenas educa, é educado, em diálogo com o educando que, ao ser educado, também educa". O diálogo, na concepção de Freire (1987), é mais do que uma simples conversa, trata-se de uma troca de experiência entre professor e aluno, dessa forma, o professor poderá:

\footnotetext{
Entender o universo simbólico em que nosso aluno está inserido, qual sua cultura primeira, qual sua tradição cultural, étnica e religiosa, a que meios de comunicação social tem acesso, a que grupos pertence, pode facilitar o aprendizado [...]. Permitir que sua visão de mundo possa aflorar na sala de aula, dando possibilidade de que perceba as diferenças estruturais, tanto de procedimentos como de conceitos, pode propiciar a transição e a retroalimentação entre as diferentes formas de conhecimento de que os sujeitos dispõem. (DELIZOICOV; ANGOTTI; PERNAMBUCO, 2007, p. 136).
}

Paulo Freire (1996, p. 139) chama a atenção para o fato de que “[...] o desrespeito à leitura de mundo do educando revela o gosto elitista, portanto antidemocrático, do educador que, desta forma, não escutando o educando, com ele não fala. Nele deposita 
seus comunicados". Ao contrário dessa lógica, os depoimentos dos professores entrevistados reforçam a preocupação em assegurar o diálogo na relação com os alunos em sala de aula:

[...] no diálogo, não tenho outra forma. No começo da abordagem do assunto, depois a gente vai deixando o senso comum para o lado e vai introduzindo o científico (P7); [...] com o tempo eles vão conhecendo a ciência e eles mesmos vão ignorar essas coisas que não estão certas pela própria evolução do conhecimento deles (P1); [...] se você pedir para o aluno falar, ele vai falar mais, escrever ele vai reduzir muito, e você não vai captar o que ele sabe (P5); eu tento comparar alguma coisa com outra, com o que ele já tem de bagagem, [...] aí ele vai diferenciar uma coisa da outra e saber que ele precisa aprender mais, [...] aí seguir na vida (P4).

O professor P2 declarou que, além do diálogo, solicita aos alunos respostas por escrito para questões por ele propostas, visando levantar os conhecimentos dos alunos. Outros professores lançam mão da pesquisa, além do diálogo e do questionamento. Por exemplo, o professor P4, faz uso da biblioteca e da sala de informática para acessar a internet, pois, segundo ele, a pesquisa permite que o aluno participe ativamente e se interesse pelo conteúdo abordado, fazendo uso dos conhecimentos que já detém para se guiar na pesquisa.

Primeiramente, seria o questionamento mesmo, daí em diante eu já consigo saber alguma coisa, mas às vezes eu uso a pesquisa [...] eu coloco um ponto lá, uma referência e peço para eles pesquisarem. [...] A partir da pesquisa eles já conseguem me passar alguma coisa. [...] Porque, às vezes, questionando eles não falam, mas aí quando é uma coisa diferente, aí eles vão atrás, eles conseguem me passar. É um método que eu uso e que normalmente dá certo (P4).

O professor P9 destaca a questão da participação ativa dos alunos nas aulas, pois, segundo ele, pesquisando, buscando o conhecimento que está sendo discutido, o aluno pode ir se conscientizando de que existem diferentes formas de explicar o que está sendo abordado em aula.

Então, além do diálogo que é bem importante, [...] a pesquisa [...] porque a partir do momento que ele está ali, está pesquisando ele também está transformando todo aquele conhecimento que ele está tendo, 'a prof falou, mas [...] tem outros lugares que falam também'. Então, partir da pesquisa eu acho que é importante para ele estar construindo esse conhecimento (P9).

Para outro professor, os alunos expressam melhor seus conhecimentos quando são questionados e solicitados a se posicionar verbalmente: "[...] se você pedir para o aluno falar, ele vai falar mais, escrever ele vai reduzir muito, e você não vai captar o que ele sabe" (P5). Já o professor P4 considera o conhecimento do aluno da seguinte forma, “[...] Eu acho que é a comparação, então eu tento comparar [...] com o que ele já tem de 
bagagem, [...] aí ele vai diferenciar uma coisa da outra e saber que ele precisa aprender mais" (P4).

Os professores entrevistados evidenciaram que não realizam propriamente uma problematização, na medida em que não colocam em xeque a concepção do aluno, pois vão trabalhando o conteúdo sistematizado paralelamente ao conhecimento do aluno. Essa dinâmica, que exige esforço do professor, pode não ser capaz de levar o aluno a reconhecer as contradições de suas concepções e, assim, compreender que há outros conhecimentos que podem melhor ajudá-lo a enfrentar os problemas.

O professor P5 acredita realizar a problematização, agindo da seguinte forma:

Dando exemplos, à medida que você vai estudando com o aluno certo conteúdo, você vai passando exemplos que ele vê no dia a dia, então a gente fala de um assunto, da indústria, da população, da influência da indústria na população, e aí você vai dando exemplos práticos [...], a influência que a indústria tem na ocupação do espaço. Daí tu fala assim: porque que as pessoas querem morar lá naquele bairro que tem uma empresa, que tem uma indústria, que tem um shopping, que tem comércio, aí você vai dando exemplos, aí ele percebe que aquele lugar na cidade o lugar que ele mora tem essa influência e ele vai percebendo que tem alguma coisa científica, que tem alguma coisa que explica aquele caso, que muitas vezes ele não tem ideia que tem uma explicação lógica. (P5).

Observa-se no depoimento que, embora o professor lance alguns questionamentos aos alunos, ele mesmo cita exemplos, evidenciando que sua expectativa é de que o aluno vá incorporando o conhecimento narrado. Não há um problema que desafie o aluno a se posicionar com os conhecimentos que tem e, através da problematização do professor, reconhecer que necessita de outros conhecimentos para enfrentar o desafio proposto.

Já o professor P6 declarou lançar mão de exemplos práticos, debates, buscando os conhecimentos dos alunos. "Sempre no diálogo, na conversa, localização no mapa, exemplos da realidade, sempre pegando fatos reais, fatos que acontecem no cotidiano, sempre colocando o aluno no contexto, [...] então [...] com diálogo, com debate, eles vão colocando" (P6). Esse professor, embora procure trabalhar de forma a contextualizar o conteúdo abordado em sala de aula, e dessa forma levantar as concepções dos alunos, não problematiza os conhecimentos prévios, apenas, assim como o professor P5, vai realizando narrativas, não insere um problema para ser enfrentado pelo aluno.

O professor P1 acredita que os alunos vão deixando de lado seus conhecimentos prévios, à medida que ele vai relatando descobertas científicas, como se a simples informação bastasse para eles se apropriarem do conhecimento científico. Podemos dizer que a dinâmica utilizada por esse professor também se aproxima da narrativa, assim como a dos professores P5 e P6.

[...] com as próprias descobertas que foram feitas, [...] como por exemplo da medicina, ou da própria Geografia que quando o homem conseguiu atingir o espaço [...]. O uso da cartografia e da matemática dentro dos parâmetros da Geografia 
para elaboração de mapas, a situação de como era no passado que as pessoas não tinham as fórmulas medicinais que existem hoje, que as pessoas morriam por problema de gripe, às vezes por não ter um antibiótico. Esses exemplos do que o homem atingiu com o estudo da ciência é o que eu costumo usar na sala de aula. (P1).

O Professor P10 referiu-se a uma dinâmica que utiliza ao iniciar a discussão, dando um exemplo sobre cartografia:

[...] geralmente, quando eu vou trabalhar cartografia, então eu começo assim: imagine que vocês estão na rua, você agora pega um papel, você vai desenhando, à direita tem comércio tal, à esquerda tem tal, daí você vai indo, mas, daqui a pouco, [...] terminou o papel, daí que eu entro no assunto, como é que a gente faz o mapa (P10).

Com uma atividade prática, o professor P10 levou os alunos a conscientizarem-se da necessidade de se apropriar de conhecimentos sobre escala cartográfica. Ele não precisou impor um conceito cientificamente aceito sobre cartografia e escala cartográfica, apenas inseriu o conhecimento científico de forma contextualizada, através de uma atividade prática que aproxima-se de uma concepção ativa de ensino-aprendizagem (LIBÂNEO, 1990).

Os professores P3 e P7 responderam que buscam conscientizar os alunos de que o conhecimento científico pode melhor contribuir para compreensão de determinado assunto, através de textos e imagens:

Com textos informativos, filmes, documentários, alguma coisa assim que possa ajudá-los a entenderem o conhecimento científico (P7). Eu costumo usar figuras, porque se você visualiza, você acaba aprendendo melhor, aí eu sempre levo para eles figuras, eu faço slides, mostrando o que acontece e o que é, é uma forma de acabarem percebendo que não é só o que eles trazem de bagagem de casa (P3).

As ferramentas didáticas relatadas nos depoimentos dos professores constituem elementos fundamentais na introdução de conhecimentos sistematizados, obviamente, depois da problematização que, de acordo com os depoimentos, não foi propriamente realizada, tomando como base o que recomendam Delizoicov; Angotti; Pernambuco (2007). O professor pode dispor da melhor estrutura, de tecnologia de ponta, sala adaptada à sua disciplina, porém, se não usar esses meios de uma maneira que propicie aos alunos relacionarem o conhecimento sistematizado aos seus saberes prévios, o professor poderá estar apenas fazendo relatos.

O professor P8 refere-se ao embasamento teórico, pois, segundo ele o docente deve estar preparado para planejar estratégias didáticas que considerem os conhecimentos dos alunos e propiciem sua problematização. Esse professor chama a atenção para a importância da formação do docente, uma vez que o embasamento teórico e metodológico se adquire na fase de formação, quer inicial ou continuada. Esse professor relatou 
como busca trabalhar a temática urbanização em sala de aula, ressaltando a importância do embasamento teórico.

Então, se o professor não tiver um embasamento teórico, não tiver um conhecimento em relação ao conteúdo que ele está trabalhando, vai ser mais complicado. A gente está trabalhando urbanização porque é importante você diagnosticar as causas, os problemas, que problemas urbanos a gente vivencia com isso, dá para trazer para nossa realidade, associar com teu dia a dia. Então, se o teu professor não tiver conhecimento, embasamento teórico, ele também não vai conseguir fazer essa ponte entre o conhecimento comum e o científico. (P8).

A heterogeneidade de cada turma demanda diferentes formas de trabalho, para que não se reproduza a ideia expressa no relato do professor P1, que, ao ser questionado se os alunos conseguiam ascender dos conhecimentos prévios para os conhecimentos científicos, respondeu:

\footnotetext{
Alguns conseguem, outros não, tem muitos [...] que ficam no conhecimento prévio, com os quais é preciso retomar várias vezes assuntos bem simples. Por exemplo, perguntar para eles sobre os movimentos da Terra, o que é globalização, ou como que é processo de Industrialização, o que é o setor primário, secundário, terciário, outros assimilam mais rápido e outros precisam de várias coisas repetidas para eles poderem assimilar isso. (P1).
}

Para o professor P1, a repetição do conteúdo para os alunos que apresentam alguma dificuldade de compreensão poderá ser a solução. Não considera o fato de que cada aluno tem uma característica, uma dificuldade, um nível de conhecimento específico. É necessário que o professor identifique qual o obstáculo a ser enfrentado, para que o aluno possa compreender o que está sendo abordado.

Sobre a "crença" de que a repetição ajuda no processo ensino-aprendizagem, Bachelard (1996, p. 23) adverte que “[...] Os professores [...] imaginam que o espírito começa como uma aula, que é sempre possível reconstruir uma cultura falha, pela repetição da lição, que se pode fazer entender uma demonstração repetindo-a ponto a ponto". Para o autor, essa "crença" pode se transformar em um obstáculo pedagógico, pois nega-se que cada aluno tem conhecimentos anteriores e que precisam ser considerados e problematizados, para que possam ser transformados.

Diante das distintas compreensões e posições dos professores, pode-se dizer que eles lançam mão de diferentes formas para identificar as concepções alternativas do aluno. Lançam mão de pesquisas, materiais concretos, filmes, documentários, gravuras, exemplos de descobertas científicas, que são, na realidade, estratégias que se aproximam mais da motivação do que da problematização propriamente dita. Assim, parece compreender que problematizar é o mesmo que motivar ou contextualizar.

Quanto à inserção dos conhecimentos sistematizados nas aulas, os professores pressupõem que seja possível ao aluno alterar seu conhecimento prévio pelo simples acesso 
ao conhecimento científico, como em alguns depoimentos. Muitos docentes procedem segundo uma concepção ativa (LIBÂNEO, 1990) de ensino-aprendizagem, segundo a qual há participação dos alunos através de atividades planejadas, mas, mesmo assim, distanciam-se da problematização.

Pode-se dizer que, apesar dos professores demonstrarem que lançam mão de distintas estragégias durante o desenvolvimento do processo de ensino-aprendizagem, ainda não conseguem realizar a problematização e trabalhar a partir dos conhecimentos prévios dos alunos.

\section{Considerações finais}

Neste texto, buscou-se discutir qual a compreensão dos professores entrevistados sobre os conhecimentos prévios dos alunos e como procedem durante o processo ensino-aprendizagem. Os resultados indicaram que os docentes compreendem o que é conhecimento prévio, mas não trabalham de forma a problematizá-los consistentemente, ou seja, não lançam problemas e perguntas desafiadores, que contenham contradições, motivando, assim, os alunos a buscar outros conhecimentos, no caso, o científico. A maioria dos professores, em seus relatos, demonstrou não ter clareza sobre como proceder para realizar a problematização, e por vezes, pressupõe que contextualizar os conhecimentos científicos com o cotidiano do aluno seja suficiente para que ocorra a problematização. Crenças como essa podem impedir que o professor provoque a reflexão sobre o que está sendo discutido, e que o aluno faça uma relação com a sua realidade. Isso pode gerar um obstáculo pedagógico, levando os alunos a resistirem ao novo conhecimento.

Provavelmente, os professores não tiveram, durante a formação inicial ou continuada, discussões que lhes permitissem trabalhar de forma problematizadora e dialógica. Assim sendo, há necessidade de que os cursos de licenciatura instrumentalizem o professor, de tal forma que se conscientize da necessidade de se aproximar dialogicamente dos conhecimentos prévios dos alunos para problematizá-los e planejar suas aulas a partir desses conhecimentos, visando superá-los ou minimizar sua influência no aprendizado do aluno, para que ele veja sentido e significado nos conhecimentos científicos introduzidos na aula.

As discussões apresentadas neste texto não se esgotam, há a necessidade de novos estudos, buscando alternativas para que o processo ensino-aprendizagem propicie, cada vez mais, a construção e transformação de conhecimentos pelos alunos.

Recebido em julho de 2016 e aprovado em agosto de 2016 


\section{Referências}

ALVES, Solange Maria. Freire e Vigotski: um diálogo entre a pedagogia freireana e a psicologia histórico-cultural. Chapecó: Argos, 2012.

BACHELARD, Gaston. A formação do espírito científico: contribuições para uma psicanálise do conhecimento. Tradução Estela dos Santos Abreu. Rio de Janeiro: Contraponto, 1996.

A epistemologia. Lisboa: 70, 2001.

BELLUCO, Alex; CARVALHO, Ana M. Pessoa. Uma proposta de sequência de ensino investigativa sobre quantidade de movimento, sua conservação e as leis de Newton. Caderno Brasileiro de Ensino de Física, v. 31, n. 1, p. 30-59, abr. 2014.

DELIZOICOV, Demétrio; ANGOTTI, José André; PERNAMBUCO, Marta Maria. Ensino de Ciências: fundamentos e métodos. 2. ed. São Paulo: Cortez, 2007.

FEIJÓ, Natanael. O conhecimento prévio do aluno e o processo ensino-aprendizagem: um diálogo com professores. 2015. 106 f. Dissertação (Mestrado em Educação) - Universidade Comunitária da Região de Chapecó - Unochapecó, Chapecó, 2015.

FREIRE, Paulo. Pedagogia do oprimido. São Paulo: Paz e Terra, 1987.

Conscientização: teoria e prática da libertação uma introdução ao pensamento de Paulo Freire. São Paulo: Moraes, 1980.

Pedagogia da autonomia: saberes necessários à prática educativa. São Paulo: Paz e Terra, 1996.

GAMBOA, Silvio Sanches. Projetos de pesquisa, fundamentos lógicos: a dialética entre perguntas e respostas. Chapecó: Argos, 2013

LAVILLE, Christian; DIONNE, Jean. A construção do saber: manual de metodologia da pesquisa em ciências. Porto Alegre: Artmed; Belo Horizonte: Editora UFMG, 1999.

LIBÂNEO, José Carlos. Didática. São Paulo. Editora Cortez, 1990.

MESSEDER NETO; PINHEIRO, Barbara C. S; ROQUE, Nídia Franco. Improvisações Teatrais no Ensino de Química: Interface entre Teatro e Ciência na Sala de Aula. Química nova na Escola, v. 35, n. 2, p. 100-106, maio 2013.

MINAYO, Maria Cecília de Souza. O desafio do conhecimento: pesquisa qualitativa em saúde. São Paulo: Hucitec, 2008.

MOREIRA, Marco Antonio; MASINI, Elcie F. Aprendizagem significativa: a teoria de David Ausubel. São Paulo: Centauro, 2001.

PERELMAN, Chaïm; OLBRECHTS, Tyteca. Tratado da argumentação: a nova retórica. São Paulo: Martins Fontes, 2005.

SANTOS, Laudenides P. A relação da Geografia e o conhecimento cotidiano vivido no Lugar. Geografia Ensino \& Pesquisa, v. 16, n. 3, p. 107-122, set./dez. 2012.

TRIVIÑOS, Augusto Nibaldo Silva. Introdução à pesquisa em ciências sociais: a pesquisa qualitativa em educação. São Paulo: Atlas, 1987.

VIGOTSKI, Lev Semenovich. A formação social da mente: o desenvolvimento dos processos psicológicos superiores. Michael Cole et al. (Org.). Tradução José Cipolla Neto, Luís Silveira Menna Barreto, Solange Castro Afeche. 6. ed. São Paulo: Martins Fontes, 1998. 